\section{AB0364 DISCONTINUATION OF CONCOMITANT METHOTREXATE IN PATIENTS WITH RHEUMATOID ARTHRITIS TREATED WITH TOCILIZUMAB: AN INTERVENTIONAL STUDY}

Shuji Asai ${ }^{1}$, Toshihisa Kojima ${ }^{1}$, Nobunori Takahashi ${ }^{1}$, Yachiyo Kuwatsuka ${ }^{2}$, Masahiko Ando ${ }^{2}$, Naoki Ishiguro'. ${ }^{1}$ Nagoya University Graduate School of Medicine, Department of Orthopaedic Surgery, Nagoya, Japan; ${ }^{2}$ Nagoya University Hospital, Department of Advanced Medicine, Nagoya, Japan

Background: Methotrexate (MTX) is an important anchor drug for rheumatoid arthritis (RA) patients and is used alone or in combination with biologics. However, some patients discontinue MTX due to toxicity including gastrointestinal (Gl) disorders [1]. Thus, de-escalation of MTX while maintaining a favourable disease activity state - a challenge in RA clinical research-may be beneficial from the perspective of reducing adverse events. The efficacy of tocilizumab (TCZ) has been demonstrated in monotherapy as well as with concomitant MTX [2], opening up the possibility of MTX discontinuation in these patients if disease control can be maintained.

Objectives: This study aimed to evaluate the efficacy and safety of MTX discontinuation in RA patients with sustained low disease activity undergoing combination therapy with TCZ plus MTX.

Methods: This multicentre, open-label, uncontrolled, prospective 64-week study included RA patients maintaining low disease activity (Clinical Disease Activity Index [CDAl] $\leq 10)$ for $\geq 12$ weeks with TCZ plus MTX. MTX was discontinued following 12 weeks of biweekly administration while continuing TCZ therapy. The rescue treatments were performed if the CDAl score was $>10$ and at the discretion of the investigator and/or upon patient request. The primary endpoint was the proportion of patients maintaining low disease activity with no flare at week 36 (24 weeks after MTX discontinuation). Disease flare was defined as a CDAl score $>10$ or intervention with the rescue treatments for any reasons. Assuming that $80 \%$ of patients would maintain low disease activity at week 36,43 patients were calculated as necessary to prove the clinical feasibility of discontinuing MTX at a power of $\geq 80 \%$ with a threshold response rate of $60 \%$. Secondary endpoints were Gl symptoms, physical function, and quality of life.

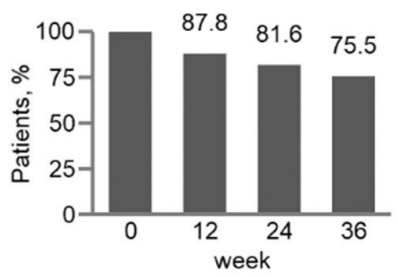

Figure 1. Proportion of patients maintaining low disease activity without a flare.

Figure 1

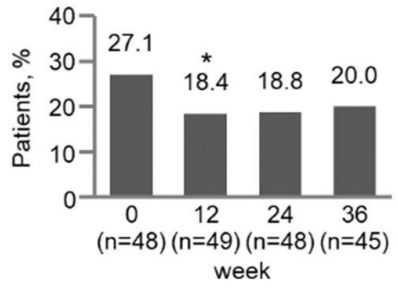

Figure 2. Prevalence of gastrooesophageal reflux disease defined as a FSSG score $\geq 8$ ${ }^{\star} P<0.05$ vs. week 0 by McNemar's test.
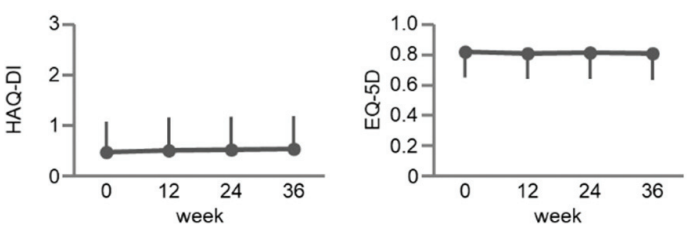

Figure 3. Changes in Health Assessment Questionnaire Disability Index (HAQ-DI) and EuroQol-5 dimension (EQ-5D) from week 0 to 36 Values represent mean (standard deviation).

Figure 3

Results: A total of 49 patients completed 36 weeks of therapy. Table 1 shows the baseline (week 0) characteristics of patients included in the efficacy analyses. The proportions $(95 \% \mathrm{Cl})$ of patients who maintained low disease activity without a flare at weeks 12,24 , and 36 were $87.8 \%$ (75.2 - 95.4\%), 81.6\% (68.0 - 91.2\%), and 75.5\% (61.1 - 86.7\%), respectively (Fig. 1). The lower limit of the $95 \% \mathrm{Cl}$ at week 36 exceeded the assumed threshold response rate of $60 \%$, demonstrating the clinical feasibility of MTX discontinuation. The prevalence of gastro-oesophageal reflux disease, defined as a Frequency Scale for Symptoms of Gastrooesophageal reflux disease score $\geq 8$, significantly decreased from week 0 to $12(27.1 \%$ to $18.4 \% ; P=0.025)$ (Fig. 2). No significant changes were observed in the HAQ-DI and EQ-5D from week 0 to 36 (Fig. 3).

Table 1. Patient characteristics at baseline (week 0)

\begin{tabular}{lccc}
\hline & \multicolumn{3}{c}{ Total, $\mathrm{n}=49$} \\
\hline Age, years & 62 & \pm & 10 \\
\hline Female,\% & 84 & & \\
Weight, kg & 55 & \pm & 11 \\
Disease duration, years & 11 & \pm & 8 \\
Route of TCZ, intravenous/ & $65 / 35$ & & \\
subcutaneous,\% & & & \\
Rheumatoid factor positive,\% & 79 & & \\
Anticyclic citrullinated peptide positive,\% & 90 & & \\
MTX dose, mg/week & 8.2 & \pm & \\
Use of glucocorticoids, $\%$ & 29 & & \\
CDAl & 2.7 & \pm & \\
CDAl $\leq 2.8, \%$ & 67 & & \\
CRP, mg/dl & 0.04 & \pm & 0.06 \\
HAQ-DI & 0.472 & \pm & 0.613 \\
EQ-5D & 0.822 & \pm & 0.170 \\
\hline
\end{tabular}

Data are shown as mean \pm SD or percentage.

Conclusion: Discontinuation of concomitant MTX is clinically feasible for maintaining low disease activity, and may be beneficial from the perspective of reducing Gl symptoms in RA patients treated with TCZ.

\section{REFERENCES}

[1] Bologna C, et al. Br J Rheumatol 1997;36:535-40.

[2] Dougados M, et al. Ann Rheum Dis 2013;72:43-50.

Disclosure of Interests: Shuji Asai Speakers bureau: AbbVie, Astellas, Bristol-Myers Squibb, Chugai, Daiichi-Sankyo, Eisai, Janssen, Takeda, and UCB Japan, Toshihisa Kojima Grant/research support from: Chugai Pharmaceutical (Investigator Initiated Study), Novartis, Nippon Kayaku, Eli Lilly, Eisai, Speakers bureau: Chugai Pharmaceutical, Takeda Pharmaceutical, Pfizer, Eli Lilly Japan, Bristol Myers Squibb, Ono Pharmaceutical, Daiichi Sankyo, Astelas, UCB, Janssen Pharmaceutical, Tanabe Mitsubishi, Nobunori Takahashi Speakers bureau: AbbVie, Bristol-Myers Squibb, Chugai, Eisai, Mitsubishi Tanabe, and Pfizer. YS has received speakers' fees from Astellas, Bristol-Myers Squibb, and Ono, Yachiyo Kuwatsuka: None declared, Masahiko Ando: None declared, Naoki Ishiguro Grant/research support from: AbbVie, Asahi Kasei, Astellas, Chugai, Daiichi-Sankyo, Eisai, Kaken, Mitsubishi Tanabe, Otsuka, Pfizer, Takeda, and Zimmer Biomet, Consultant for: Ono, Speakers bureau: Astellas, Bristol-Myers Squibb, Daiichi-Sankyo, Eli Lilly, Pfizer, and Taisho Toyama DOI: 10.1136/annrheumdis-2019-eular.221

Figure 2 